Article

\title{
Catalytic Hydrodechlorination of Chlorophenols in a Continuous Flow Pd/CNT-Ni Foam Micro Reactor Using Formic Acid as a Hydrogen Source
}

\author{
Jun Xiong ${ }^{*}+(\mathbb{D})$ and Ying $\mathrm{Ma}^{\dagger}$ \\ School of Pharmacy, Zunyi Medical University, Guizhou 510640, China; maying160@163.com \\ * Correspondence: xiongjun@zmc.edu.cn; Tel.: +86-0851-2864-2341 \\ + These authors contributed equally to this work.
}

Received: 16 December 2018; Accepted: 8 January 2019; Published: 12 January 2019

check for updates

\begin{abstract}
Catalytic hydrodechlorination (HDC) has been considered as a promising method for the treatment of wastewater containing chlorinated organic pollutants. A continuous flow $\mathrm{Pd} /$ carbon nanotube (CNT)-Ni foam micro reactor system was first developed for the rapid and highly efficient HDC with formic acid (FA) as a hydrogen source. This micro reactor system, exhibiting a higher catalytic activity of HDC than the conventional packed bed reactor, reduced the residence time and formic acid consumption significantly. The desired outcomes (dichlorination $>99.9 \%$, 4-chlorophenol outlet concentration $<0.1 \mathrm{mg} / \mathrm{L}$ ) can be obtained under a very low FA/substrate molar ratio (5:1) and short reaction cycle (3 min). Field emission scanning electron microcopy (FESEM) and deactivation experiment results indicated that the accumulation of phenol (the main product during the HDC of chlorophenols) on the Pd catalyst surface can be the main factor for the long-term deactivation of the Pd/CNT-Ni foam micro reactor. The catalytic activity deactivation of the micro reactor could be almost completely regenerated by the efficient removal of the absorbed phenol from the Pd catalyst surface.
\end{abstract}

Keywords: catalytic hydrodechlorination; micro reactor; chlorophenols; Pd catalyst

\section{Introduction}

Chlorophenols (CPs), existing widely in polluted groundwater and the wastewater effluents of industry [1,2], have been listed as priority pollutants in many countries because of their high toxicity, adverse environmental impacts and poor biodegradability [3-5]. For the safe disposal of these highly toxic chlorinated organic pollutants, many detoxification techniques such as biodegradation [6], photochemical degradation [5], advanced oxidation $[7,8]$ and catalytic hydrodechlorination $[9,10]$ have been proposed. Among the available water treatment techniques mentioned above, hydrodechlorination (HDC) presents the advantages of greater flexibility, low energy consumption and relatively safe by-products, showing promising prospects in the treatment of wastewater containing chlorinated organic pollutants [11-13].

Molecular hydrogen $\left(\mathrm{H}_{2}\right)$ is the most widely employed hydrogen source for HDC [10,14-18]. However, the low $\mathrm{H}_{2}$ utilization efficiency caused by its very low solubility in water $(0.84 \mathrm{mM}$, at 288 $\mathrm{K}$ and $\left.\mathrm{P}_{\mathrm{H} 2}=100 \mathrm{kPa}\right)[19,20]$, and the low process safety associated with hydrogen gas usage [21,22], may lead to some adverse influences during the treatment of wastewater on a large scale through HDC. To overcome these drawbacks, other potential hydrogen sources, including isopropanol, hydrazine, formic acid and formate, have been reported $[19,20,23,24]$. Formic acid, with high solubility in water, has been proven to be a promising alternative hydrogen source of HDC [14,20].

The HDC of chlorinated organic compounds are generally performed in a conventional batch reactor with a powder Pd catalyst [11,25-28]. A high formic acid (FA) consumption (FA/substrate 
molar ratio $\geq 35: 1$ ) and relatively long reaction time (tens of minutes or several hours) is required for a high dechlorination of the substrate during HDC, as FA is utilized to provide hydrogen $[14,19,20,23]$. Furthermore, the inherent difficulty of scale-up is still a challenge during the industrial application of a batch reactor system $[29,30]$. The application of a small-scale continuous flow reactor (micro reactor) system may offer some advantages, especially for heterogeneous catalytic reactions such as HDC, over a conventional batch reactor system [29]. The micro reactor, with short diffusion paths and large interfacial areas, can provide efficient mixing and fast mass transfer during HDC, contributing to the achievement of desired outcomes (e.g., high dechlorination, low FA consumption and short reaction cycle) [30-32]. Scaling up a continuous reactor system is also generally easier than scaling up a batch reactor system $[30,33,34]$. Thus, it is interesting to develop a new micro reactor system for HDC in continuous flow.

A carbon nanotube (CNT)-Ni foam-supported Pd catalyst has been found to be an excellent catalyst candidate for HDC [35]. Notably, this monolithic Pd/CNT-Ni foam composite catalyst can also be utilized as a micro reactor, due to its highly porous channel with a micrometer size and well-dispersed active Pd catalyst on the surface of the micro channel. Herein, we report the usage of a micro reactor system for conducting HDC in continuous flow for the first time. Our aim is to develop a new micro reactor system possessing a high catalytic HDC performance. The $\mathrm{Pd} / \mathrm{CNT}-\mathrm{Ni}$ foam micro reactor system was configured and its HDC of CPs was evaluated in detail by using the safe and efficient formic acid as a hydrogen source. Finally, the long-term deactivation and regeneration of the $\mathrm{Pd} / \mathrm{CNT}-\mathrm{Ni}$ foam micro reactor were investigated.

\section{Results and Discussion}

\subsection{Catalyst Characterization}

Figure 1 presents Field emission scanning electron microcopy (FESEM) results of the Pd/CNT-Ni foam micro reactor. A highly porous $\mathrm{Ni}$ foam skeleton with irregular micro channels of about $150-500 \mu \mathrm{m}$ in size (Figure 1a) was found in this monolithic micro reactor. Uniformly dispersed $\mathrm{Pd}$ nanoparticles were observed on the CNT surface of the fresh Pd/CNT-Ni foam micro reactor, and their amount increased significantly with the Pd loading (Figure 1b,c). The micro reactors were used for $76 \mathrm{~h}$ and deactivated with a high-concentration phenol solution, following which similar organic layers were observed on the Pd catalyst surface (Figure 1d,e). After regeneration treatment, the organic layer covered on the Pd catalyst surface disappeared (Figure 1f), indicating an efficient removal of the absorbed organic layer from the catalyst surface during regeneration.

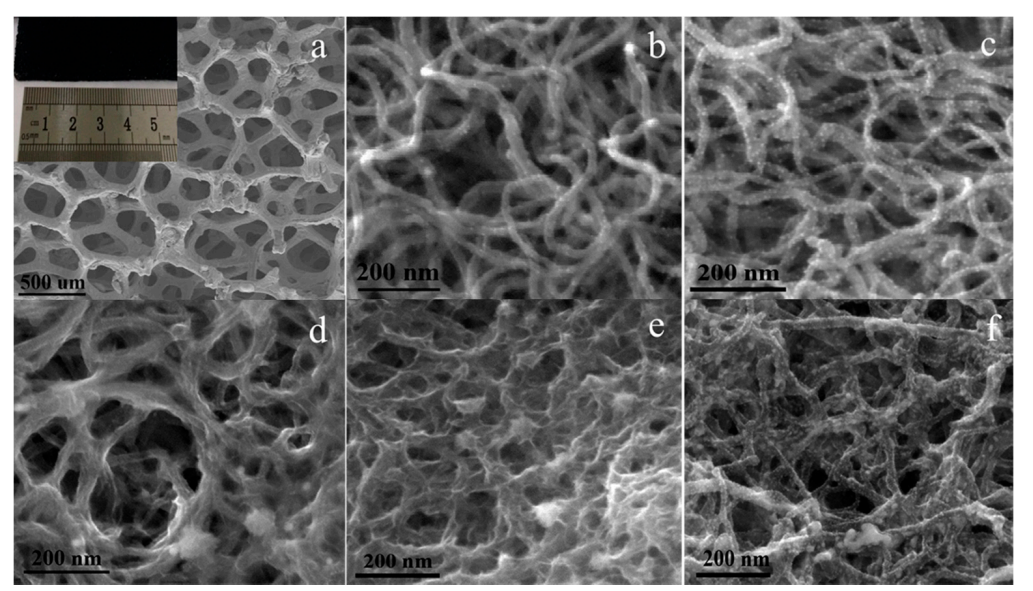

Figure 1. Field emission scanning electron microcopy (FESEM) images of 0.5 wt.\% fresh (a,c), $0.2 \mathrm{wt} . \%$ fresh (b), $0.5 \mathrm{wt}$ \% used (d), $0.5 \mathrm{wt}$.\% deactivated with phenol (e) and $0.5 \mathrm{wt} . \%$ regenerated (f) $\mathrm{Pd} /$ carbon nanotube (CNT)-Ni foam micro reactors. The inset in (a) is the photograph of the $\mathrm{Pd} / \mathrm{CNT}-\mathrm{Ni}$ foam micro reactor. 
The fresh and used Pd/CNT-Ni foam micro reactors were also investigated by TEM/HRTEM. Figure 2a shows that the Pd particles were well dispersed in a fresh Pd/CNT-Ni foam micro reactor, which is consistent with the FESEM observation. The average particle size was about $2.68 \mathrm{~nm}$ (Figure 2c). The nanoparticle composition was confirmed to be metal Pd by the HRTEM results and the corresponding fast Fourier transform (FFT). The lattice plane with the interplanar distance of $2.26 \AA$ and its corresponding FFT pattern, assigned to the (111) plane of the face-centered cubic (fcc) Pd, are presented in Figure 2e [36,37]. The Pd particle characteristics including dispersion, size distribution and composition in the used micro reactor (Figure $2 \mathrm{~b}, \mathrm{~d}, \mathrm{f}$ ) are almost the same as those presented in the fresh micro reactor, revealing the excellent stability of Pd particles during HDC.
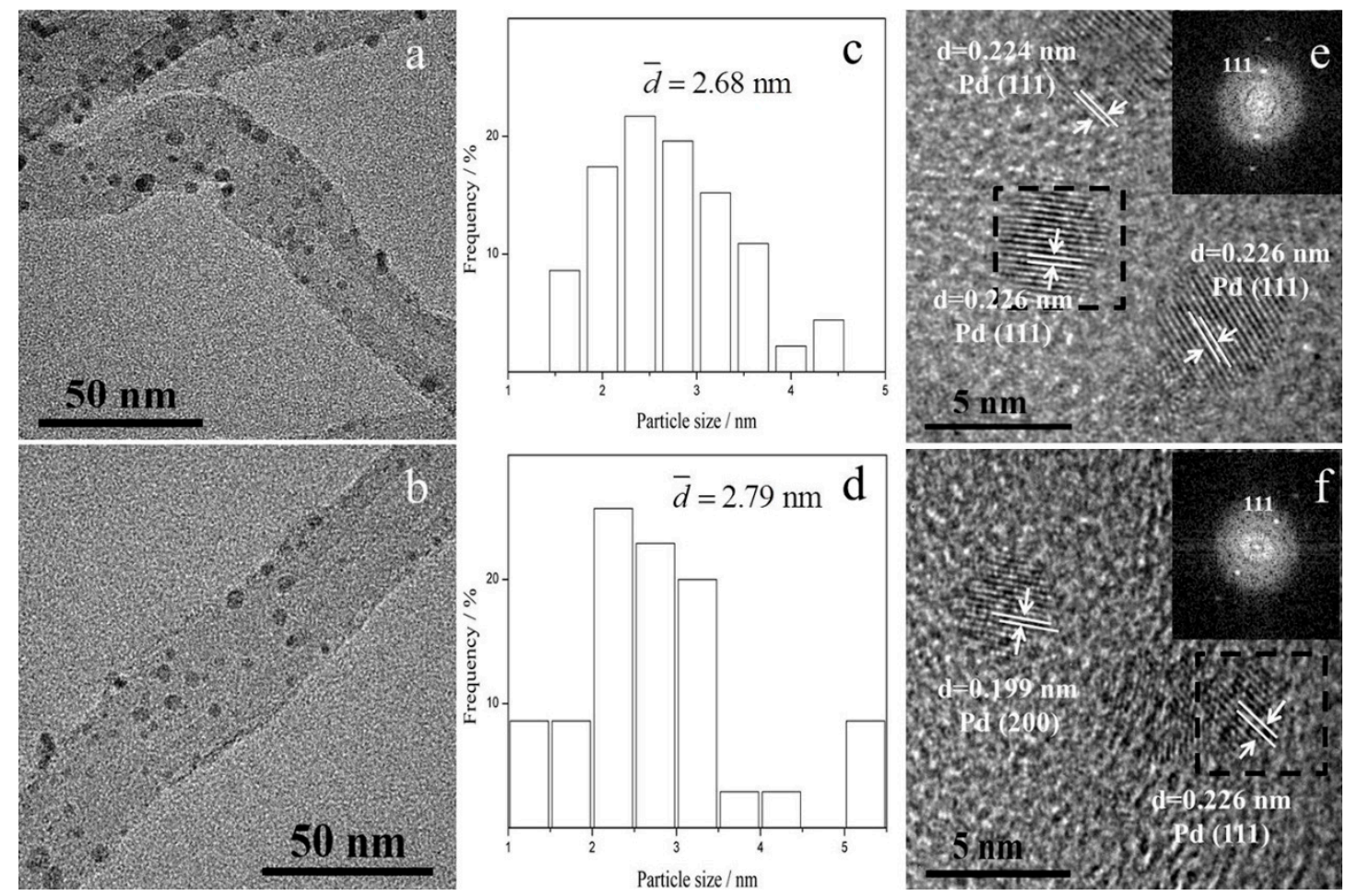

Figure 2. TEM $(\mathbf{a}, \mathbf{b})$ images and HRTEM $(\mathbf{e}, \mathbf{f})$ images of the fresh and used Pd/CNT-Ni foam micro reactors, respectively. $(\mathbf{c}, \mathbf{d})$ The corresponding particle size distribution of $(\mathbf{a}, \mathbf{b})$. The insets in $(\mathbf{e}, \mathbf{f})$ are the fast Fourier transform (FFT) patterns corresponding to the labeled regions.

\subsection{HDC of 4-CP in Continuous Flow Micro Reactor and Packed Bed Reactor}

For a comparison of the catalytic performance between the micro reactor and packed bed reactor, the HDC evaluations were controlled at analogous reaction conditions, such as the same reactor volume (about $4.8 \mathrm{~mL}$ ), residence time and FA/substrate molar ratio. As shown in Figure 3, a significant increase in dechlorination and decrease in 4-CP outlet concentration was observed when switching from the packed bed reactor to the micro reactor. Desired outcomes (dichlorination $>99.9 \%, 4-\mathrm{CP}$ outlet concentration $<0.1 \mathrm{mg} / \mathrm{L}$ ) of HDC was obtained in the micro reactor. With the reduction of the FA/substrate molar ratio from 5:1 to $2: 1$, the enhancement of catalytic activity in the micro reactor would be increased.

For HDC with the alternative hydrogen source of FA (a typical liquid-solid heterogeneous catalytic process), the reaction rate depends on the concentration of the reactants (4-CP and FA) available on the catalyst surface sites, which means that the observed catalytic activity is influenced by both the surface hydrodechlorination reaction rate and the reactants' mass transport rate from the liquid phase to the catalyst surface [34,38]. In this work, the reaction scale is reasonable enough to be the main difference between the micro reactor and packed bed reactor, because these two heterogeneous catalytic reactors 
possess the same catalyst characteristics, including active Pd loading $(0.5 \mathrm{wt} . \%)$ and $\mathrm{Pd}$ particle size (about $2.68 \mathrm{~nm}$ ). Generally, the reduction of the reaction channel to a micro size is beneficial for enhancing the mass transport rate of reactants significantly [29,31,32,39]. Therefore, a higher HDC activity was exhibited by the micro reactor. In HDC, by using FA as a hydrogen source, a higher FA concentration on catalyst surface sites is necessary to generate a sufficient $\mathrm{Pd}-\mathrm{H}$ reactive species, due to the incomplete FA decomposition during reaction [14,23]. A micro reactor with a very short diffusion distance can undoubtedly improve the refill of FA on the catalyst surface, especially under a low FA/substrate molar ratio. That is why the more obvious advantage of the micro reactor was observed under a lower FA/substrate molar ratio.

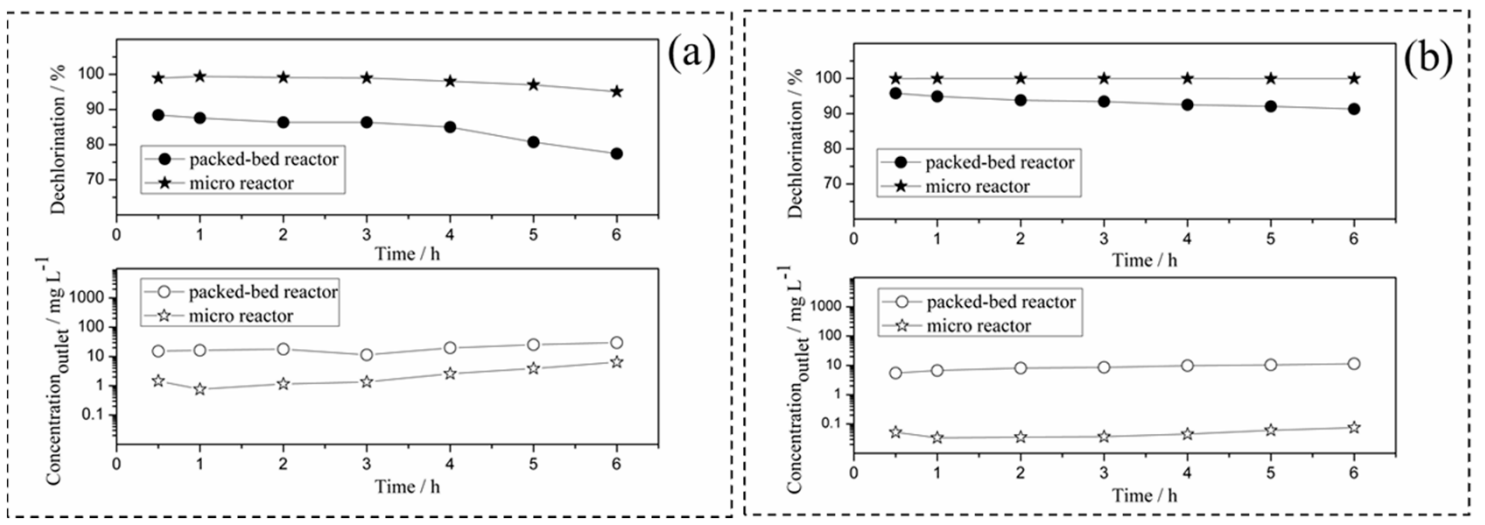

Figure 3. Hydrodechlorination (HDC) performance under 2:1 formic acid (FA)/substrate molar ratio (a) and 5:1 FA/substrate molar ratio (b) in different continuous flow reactors. Reaction conditions: residence time (3 $\mathrm{min})$, Pd loading (0.5 wt.\%), 4-chlorophenol concentration (1 mmol/L).

\subsection{HDC of 4-CP in Micro Reactor with Different Pd Contents}

Figure 4 shows 4-CP dechlorination in a continuous flow Pd/CNT-Ni foam micro reactor with different $\mathrm{Pd}$ contents. For the micro reactor without $\mathrm{Pd}$, a very low dechlorination $(<5 \%)$ of $4-\mathrm{CP}$ was found. A significant decrease of 4-CP dechlorination from $80.2 \%$ to $47.8 \%$ during the first $6 \mathrm{~h}$ was presented by the micro reactor with $0.1 \mathrm{wt} . \% \mathrm{Pd}$. The catalytic activity and stability were obviously enhanced by the increase of Pd loading from 0.1 to $0.5 \mathrm{wt} . \%$. A very highly efficient and stable $\mathrm{HDC}$ of $4-\mathrm{CP}$ was exhibited by the micro reactor with $0.5 \mathrm{wt} . \% \mathrm{Pd}$. No significant changes of 4-CP dechlorination and catalytic stability were observed with the further increase of Pd content in the micro reactor from 0.5 to $2 \mathrm{wt} . \%$.

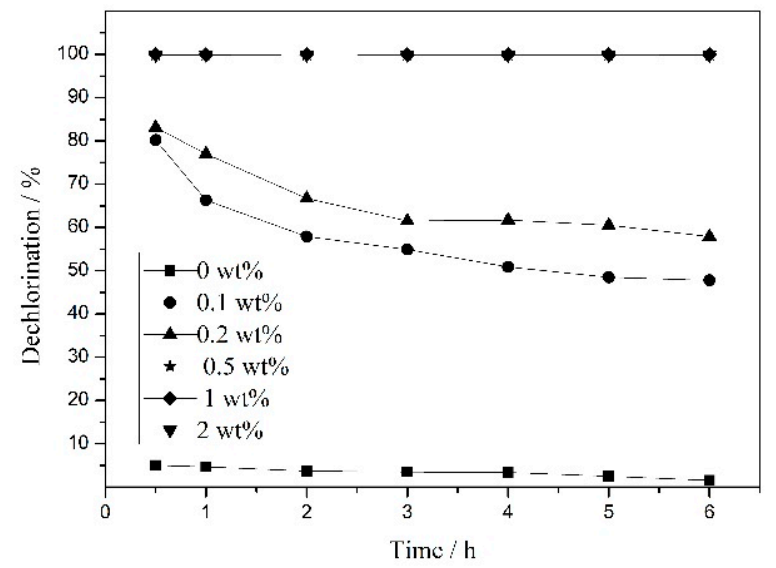

Figure 4. Dechlorination of 4-CP during an HDC reaction in a Pd/CNT-Ni foam micro reactor with different Pd loadings. Reaction conditions: residence time (3 min), FA/substrate molar ratio (5:1), 4-chlorophenol concentration (1 mmol/L). 
In the HDC mechanism (Scheme 1) [38], the CPs (4-CP) were adsorbed on the surface sites of the Pd catalyst and consumed by the surface hydrodechlorination reaction, involving the adsorbed atomic hydrogen and adsorbed CPs. The accumulation of 4-CP on the catalyst surface may occur, as the surface reaction rate is very low. For the micro reactors with a lower Pd loading (less than $0.2 \mathrm{wt} . \%)$, the surface reaction rate is expected to be lower, due to the limited availability of active Pd sites (Figure 1b). Jadbabaei et al. [38] reported the obvious catalytic deactivation caused by the 4 -CP accumulation on the surface of a catalyst with a low Pd loading $(<0.44 \mathrm{wt}$.\%) during the HDC of 4-CP. This phenomenon was also observed during our study. For the micro reactor with $0.1 \mathrm{wt} . \%$ $\mathrm{Pd}$, the $4-\mathrm{CP}$ dechlorination decreased rapidly from $80.2 \%$ to $47.8 \%$. The catalyst active surface sites in the low Pd loading micro reactor were gradually covered by the accumulating 4-CP during the reaction, resulting in the reduction of the HDC catalytic activity. Thus, the micro reactors with lower Pd loadings (0.1 and $0.2 \mathrm{wt} . \%)$ present lower catalytic activity and stability. As the Pd loading in the micro reactor increased, the surface reaction could be accelerated by the increase in active Pd sites (Figure 1b,c) [40,41]. Additionally, the accumulation of 4-CP on the catalyst surface was alleviated or even eliminated. Therefore, high catalytic activity (dechlorination $>99.9 \%$ ) and stability was exhibited by the micro reactor with a relatively high Pd loading $(\geq 0.5 \mathrm{wt} . \%)$.

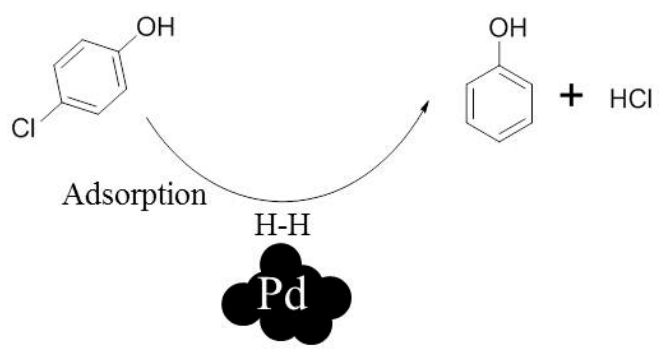

Scheme 1. Mechanism of HDC on the Pd catalyst surface.

\subsection{HDC of 4-CP in Micro Reactor under Different FA/Substrate Molar Ratios}

The FA decomposition rate is considered to be slower than the hydrodechlorination rate during HDC, although it can be stimulated by hydrodechlorination simultaneously [14,20]. A high FA/substrate molar ratio is required to provide sufficient active adsorbed atomic hydrogen for a highly efficient HDC process. The influence of the FA/substrate molar ratio on the dechlorination of 4-CP during HDC in continuous flow Pd/CNT-Ni foam micro reactor was evaluated. As shown in Figure 5, the catalytic activity and stability were enhanced significantly with the increase of the FA/substrate molar ratio from 1:1 to 5:1. The lower activity and stability under low FA/substrate molar ratios (1:1 and 2:1) may also be attributed to the low 4-CP consumption rate on the catalyst surface caused by the insufficiently active adsorbed atomic hydrogen under these conditions $[19,38]$. Notably, the $\mathrm{FA} /$ substrate molar ratio required for the almost complete dechlorination of 4-CP during HDC in our study was far less than that reported in other works $[20,23]$.

\subsection{The Longevity, Deactivation and Regeneration of Pd/CNT-Ni Foam Micro Reactor}

An HDC durability test was conducted for the evaluation of long-term catalytic stability in a continuous flow Pd/CNT-Ni foam micro reactor. Figure 6a shows the 4-CP dechlorination as a function of reaction time. The 4-CP dechlorination maintains a very high and stable value ( $\geq 99.9 \%)$ during the initial $30 \mathrm{~h}$. However, a gradual loss of catalytic activity with reaction time was observed after $30 \mathrm{~h}$. Only $60.9 \%$ dechlorination of 4-CP was found at the final 76th hour. The long-term deactivation of HDC could occur in a continuous flow Pd/CNT-Ni foam micro reactor. 


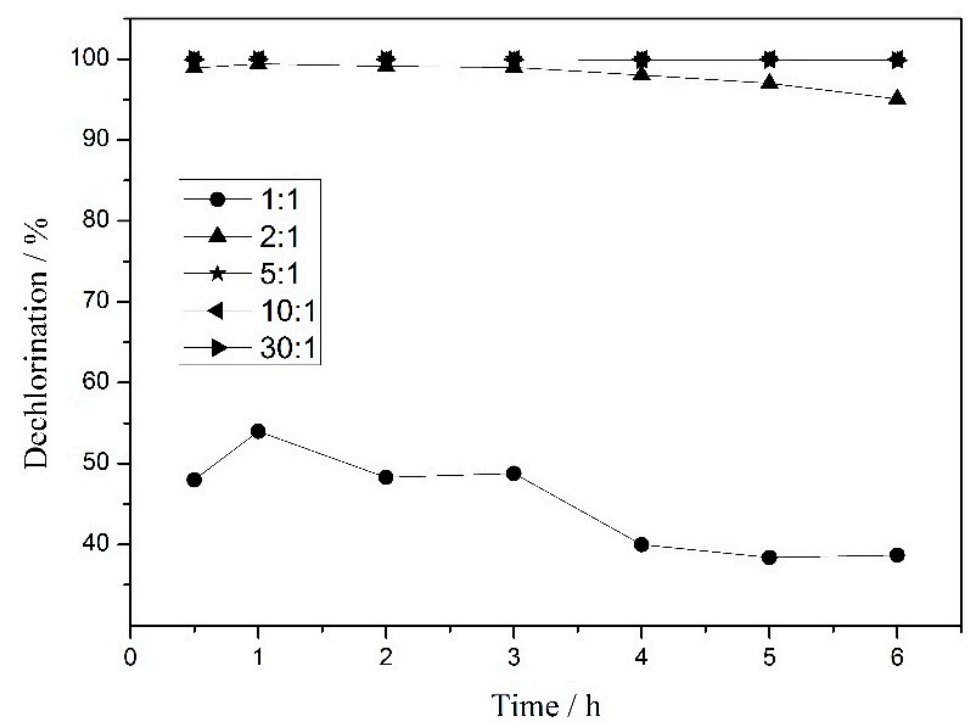

Figure 5. Dechlorination of 4-CP during HDC reaction in a Pd/CNT-Ni foam micro reactor under different FA/substrate molar ratios. Reaction conditions: residence time (3 min), Pd loading (0.5 wt. \%), 4-chlorophenol concentration $(1 \mathrm{mmol} / \mathrm{L})$.

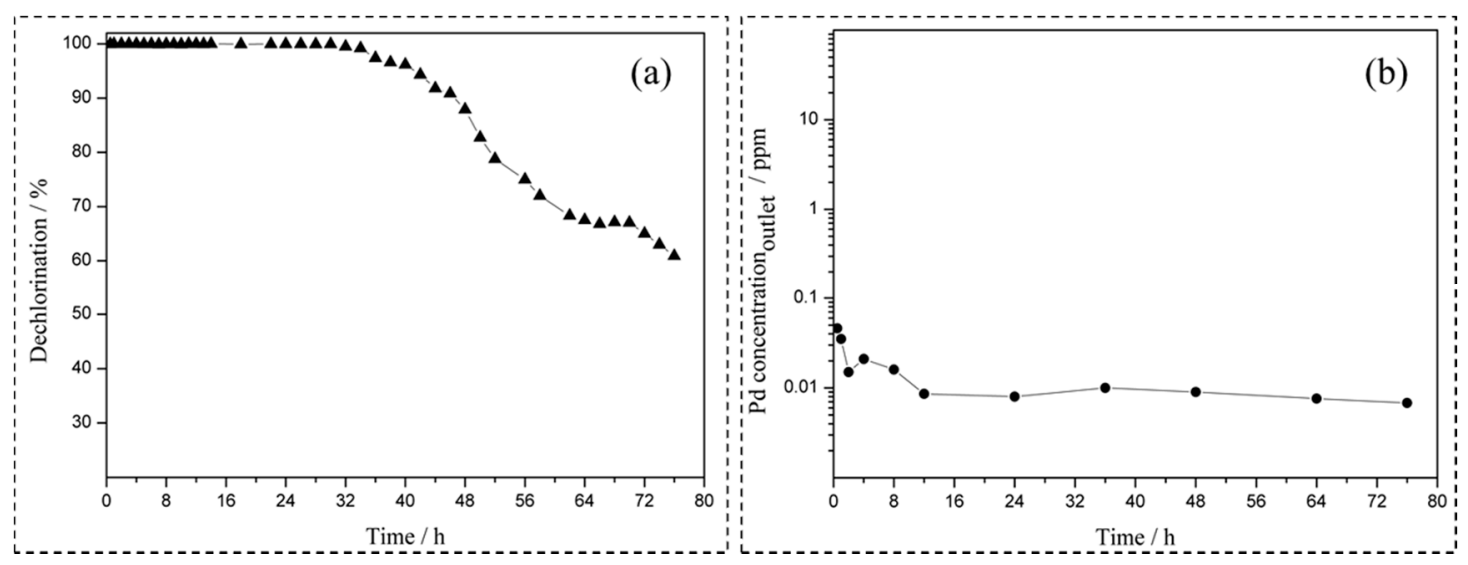

Figure 6. Dechlorination of 4-CP (a) and Pd outlet concentration (b) as a function of reaction time during HDC reaction in a Pd/CNT-Ni foam micro reactor. Reaction conditions: residence time (3 min), Pd loading (0.5 wt.\%), FA/substrate molar ratio (5:1), 4-chlorophenol concentration (1 mmol/L).

$\mathrm{HCl}$ poisoning, which may induce severe $\mathrm{Pd}$ leaching and the alteration of Pd particles through corrosive action, has been widely reported as an important factor of Pd catalyst deactivation during HDC $[12,38,42,43]$. In our study, the continuous flow operation in the micro reactor achieved a more effective removal of $\mathrm{HCl}$ from the $\mathrm{Pd}$ catalyst surface, limiting the influences of $\mathrm{HCl}$ by-products during HDC [44]. Additionally, Pd particles with excellent stability, which may result from the strong interaction between the transition metal (Pd) atoms and sp2-hybridized carbon atoms [12,45], is expected to be resistant to $\mathrm{HCl}$ poisoning during the very short residence time $(3 \mathrm{~min})$. These inferences were supported by the Pd leaching measurement and TEM/HRTEM analysis. As illustrated in Figure $6 \mathrm{~b}$, Pd leaching in the effluents of the micro reactor was very low $(<0.05 \mathrm{ppm})$ and almost undetectable $(<0.01 \mathrm{ppm})$ after the 10th hour. The dispersion, distribution and composition of $\mathrm{Pd}$ particles were also largely unchanged during 76 hours of reaction time (Figure 2). Therefore, the influence of $\mathrm{HCl}$ poisoning on the catalytic stability was not significant during $\mathrm{HDC}$ in the Pd/CNT-Ni foam micro reactor.

The fresh and used Pd/CNT-Ni foam micro reactors were further investigated by FESEM. It was found that the Pd catalyst surface in the Pd/CNT-Ni foam micro reactors was covered by an organic layer after $76 \mathrm{~h}$ (Figure 1c,d). The used Pd/CNT-Ni foam micro reactor was soaked in 
ethanol for $4 \mathrm{~h}$ to perform an organics partial desorption test. Many phenols (about $37.8 \mathrm{mg} / \mathrm{L}$ in solution), the main product for the HDC of 4-CP, were detected. To confirm the role of phenol accumulation on the deactivation of the $\mathrm{Pd} / \mathrm{CNT}-\mathrm{Ni}$ foam micro reactor, a deactivation experiment with a high-concentration phenol solution $(1 \mathrm{~mol} / \mathrm{L})$ treatment was carried out for $4 \mathrm{~h}$. A similar organic layer to that caused by phenol accumulation was observed on the catalyst surface of the deactivated micro reactor (Figure 1e). According to the HDC performance results shown in Figure 7, serious deactivation of the $\mathrm{Pd} / \mathrm{CNT}-\mathrm{Ni}$ foam micro reactor was observed. The 4-CP dechlorination decreased remarkably from almost $100 \%$ to a very low level, less than $15 \%$. Serious deactivation of HDC induced by phenol accumulation on the Pd catalyst surface was also observed in the work of Jadbabaei et. al. [38].

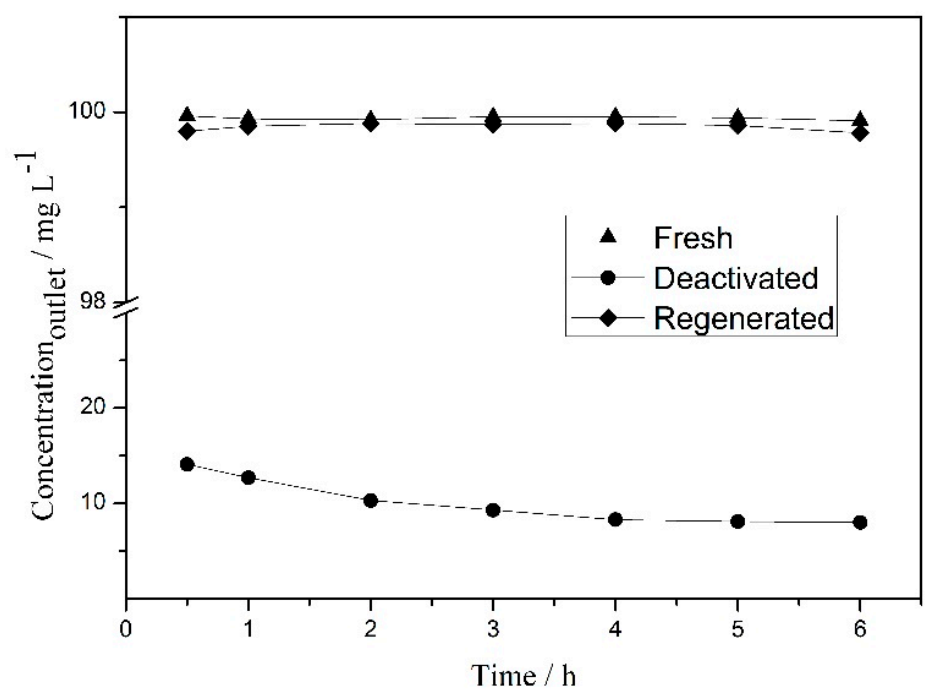

Figure 7. Dechlorination of 4-CP during HDC reaction in fresh, used and deactivated Pd/CNT-Ni foam micro reactors. Reaction conditions: residence time (3 min), Pd loading (0.5 wt.\%), FA/substrate molar ratio (5:1), 4-chlorophenol concentration (1 mmol/L).

Lastly, a deactivated Pd/CNT-Ni foam micro reactor was regenerated for $3 \mathrm{~h}$ in an argon atmosphere $\left(20 \mathrm{~mL} / \mathrm{min}\right.$ flow rate) at $250{ }^{\circ} \mathrm{C}$. An almost complete recovery of the HDC catalytic activity was presented by the regenerated micro reactor (Figure 7), due to the efficient removal of the absorbed phenol layer from the Pd catalyst surface during the regeneration process (Figure 1f). This result demonstrated that the Pd/CNT-Ni foam micro reactor system can be regenerated efficiently through a simple heating process, facilitating its practical application significantly.

\section{Materials and Methods}

\subsection{Preparation of Pd/CNT-Ni Foam Micro Reactor (Pd/CNT-Ni Foam Composite Catalyst)}

A detailed preparation of the Pd/CNT-Ni foam micro reactor has been reported in the literature [35]. The active Pd was introduced into the micro channel of a monolithic CNT-Ni foam composite through the wetness incipient impregnation method. The pretreated CNT-Ni foam composite (about $15 \mathrm{wt} . \% \mathrm{CNTs}$ ) was impregnated with an acetone solution, then calcined at $300^{\circ} \mathrm{C}$ for $2 \mathrm{~h}$. Finally, the samples were reduced with $20 \mathrm{~mL} / \mathrm{min}$ hydrogen flow at $300^{\circ} \mathrm{C}$ for $2 \mathrm{~h}$.

\subsection{Catalytic Performance Evaluation}

The HDC performance evaluations in micro reactors were carried out in a continuous flow $\mathrm{Pd} / \mathrm{CNT}-\mathrm{Ni}$ foam micro reactor system (Figure $8 \mathrm{a}$ ) at room temperature and atmospheric pressure. Seven pieces of $65 \times 6 \times 1.8 \mathrm{~mm}(\mathrm{~L} \times \mathrm{W} \times \mathrm{H})$ Pd/CNT-Ni foam micro reactor (about $1.5 \mathrm{~g}$ ) were embedded into the stainless steel reaction chamber (Figure $8 b$ ) to assemble the reactor system with 
two fixed stainless steel plates. The $4-\mathrm{CP}(1 \mathrm{mmol} / \mathrm{L})$ and FA aqueous solution with an appropriate flow rate was made to flow into a micro reactor through a micro pump. The effluent liquid products of the reactor were collected for further analysis.

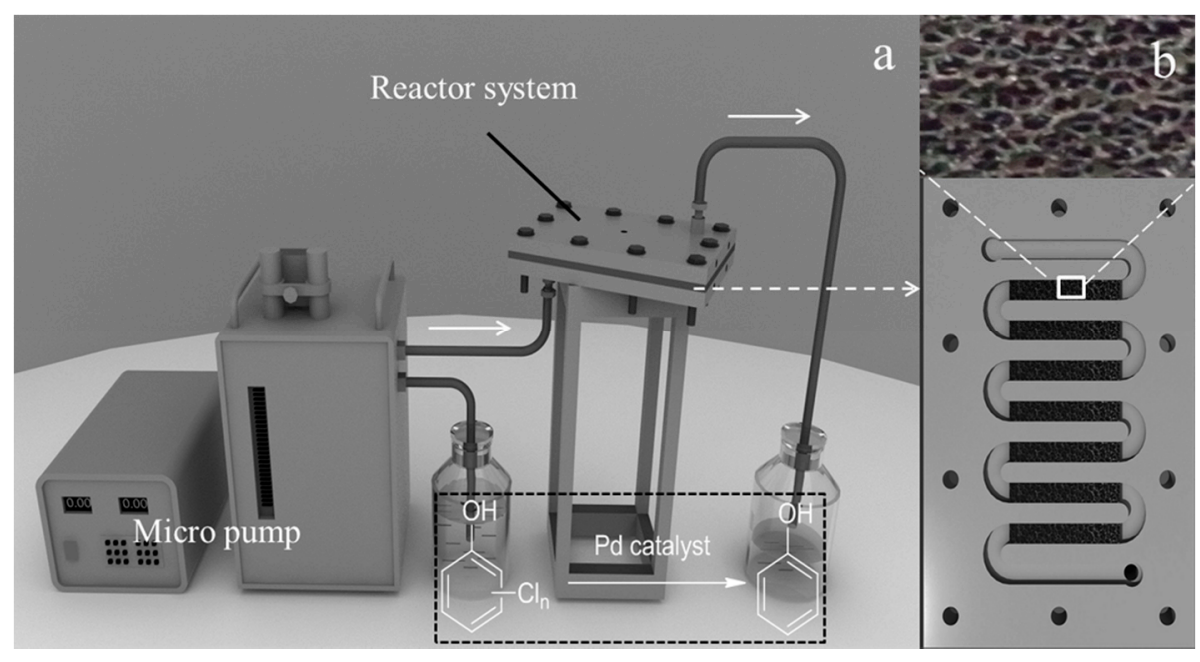

Figure 8. Sketched configuration of the continuous flow Pd/CNT-Ni foam micro reactor system (a) and the reaction chamber embedded with a Pd/CNT-Ni foam micro reactor $(\mathbf{b})$.

We also evaluated the HDC performance in a continuous flow packed bed reactor with a Pd/CNT-Ni foam composite catalyst. Small pieces of Pd/CNT-Ni foam composite catalysts $(3 \times 3 \times 1.8 \mathrm{~mm})$ were packed into a $100-\mathrm{mm}$ length of quartz tubing $(8 \mathrm{~mm}$ I.D. $)$ to assemble the packed bed reactor. The reagents aqueous solution was then pumped into the reactor, and the effluent liquid products of the reactor were collected for further analysis.

The effluent liquid samples were analyzed by high-performance liquid chromatography (HPLC) with a Zorbax XDB-C18 column (Agilent, USA) [1,12,35]. Inductively coupled plasma mass-spectrometry (ICP-MS) was employed to measure the Pd contents in the effluents.

\subsection{Catalyst Characterization}

A JSM-4800F electron microscope (JEOL Ltd., Tokyo, Japan) was employed for the field emission scanning electron microcopy (FESEM) analysis. To carry out transmission electron microscopy (TEM) and high resolution transmission electron microscopy (HRTEM) on A JEOL-2100F electron microscope (JEOL Ltd., Tokyo, Japan), the powder Pd/CNTs sample was prepared by separating it from the Ni foam skeleton through hydrochloric acid $(0.1 \mathrm{M})$ immersion and ultrasonic treatment. The tests of $\mathrm{Pd}$ concentration in the effluents were conducted through Agilent 7500a (Agilent, USA) inductively coupled plasma mass-spectrometry.

\section{Conclusions}

The HDC of CPs using FA as a hydrogen source was investigated for the first time in a continuous flow micro reactor. A continuous flow Pd/CNT-Ni foam micro reactor system was developed for the rapid and highly efficient HDC of CPs. This micro reactor system, providing a micro size reaction channel $(100-500 \mu \mathrm{m})$ and well-dispersed Pd nanoparticles $(2.68 \mathrm{~nm})$, exhibited a higher catalytic activity of HDC compared with the conventional packed bed reactor.

The influences of the Pd content and FA/substrate molar ratio on HDC performance in a continuous flow micro reactor were discussed. A very low FA/substrate molar ratio (5:1) and short reaction time ( $3 \mathrm{~min}$ ) were required to obtain the desired outcomes (dichlorination $>99.9 \%$, 4-CP outlet concentration $<0.1 \mathrm{mg} / \mathrm{L}$ ) for a micro reactor with $0.5 \mathrm{wt} . \%$ Pd loading. Moreover, the long-term deactivation of HDC, which can be mainly attributed to the phenol accumulation on the Pd catalyst 
surface, was observed. The catalytic activity deactivation of this micro reactor system can be almost completely recovered by the efficient removal of the absorbed phenol layer from the Pd catalyst surface, making it a promising candidate for the HDC of wastewater containing highly toxic chlorinated organic pollutants and other Pd-catalyzed hydrogenation reactions.

This work shows that the usage of a micro reactor system is practicable and highly efficient for HDC in continuous flow. Future plans involve the development of a new Pd-based micro reactor system with designable structures and unique physical and chemical properties, which could remove target contaminants and enable the in situ regeneration of active components simultaneously.

Author Contributions: This study was conducted through contributions of all authors. J.X. designed the study, performed the experiments, and wrote the manuscript. Y.M. was involved in performing the experiments.

Funding: This work was supported by the Natural Science Foundation of China (grant number 21463030) and the Guizhou Province Technology Department of China (grant number QKHLHZ-2014-7550).

Conflicts of Interest: The authors declare no conflict of interest.

\section{References}

1. Lan, Y.; Yang, L.; Zhang, M.; Zhang, W.; Wang, S. Microreactor of Pd nanoparticles immobilized hollow microspheres for catalytic hydrodechlorination of chlorophenols in water. Appl. Mater. Interfaces 2010, 2, 127-133. [CrossRef] [PubMed]

2. Zhou, S.; Jin, X.; Sun, F.; Zhou, H.; Yang, C.; Xia, C. Combination of hydrodechlorination and biodegradation for the abatement of chlorophenols. Water Sci. Technol. 2012, 65, 780-786. [CrossRef] [PubMed]

3. Sun, C.; Wu, Z.; Mao, Y.; Yin, X.; Ma, L.; Wang, D.; Zhang, M. A highly active Pd on Ni-B bimetallic catalyst for liquid-phase hydrodechlorination of 4-chlorophenol under mild conditions. Catal. Lett. 2011, 141, 792-798. [CrossRef]

4. Cui, X.; Zuo, W.; Tian, M.; Dong, Z.; Ma, J. Highly efficient and recyclable Ni MOF-derived N-doped magnetic mesoporous carbon-supported palladium catalysts for the hydrodechlorination of chlorophenols. J. Mol. Catal. A Chem. 2016, 423, 386-392. [CrossRef]

5. Yin, L.F.; Shen, Z.Y.; Niu, J.F.; Jing, C.; Duan, Y.P. Degradation of pentachlorophenol and 2,4-dichlorophenol by sequential visible-light driven photocatalysis and laccase catalysis. Environ. Sci. Technol. 2010, 44, 9117-9122. [CrossRef] [PubMed]

6. Kao, C.M.; Chen, K.F.; Chen, Y.L.; Chen, T.Y.; Huang, W.Y. Biobarrier system for remediation of TCE-contaminated aquifers. Bull. Environ. Contam. Toxicol. 2004, 72, 87-93. [CrossRef] [PubMed]

7. Untea, I.; Orbeci, C.; Tudorache, E. Oxidative degradation of 4-chlorophenol from aqueous solution by photo-fenton advanced oxidation process. Environ. Eng. Manag. J. 2006, 5, 661-674. [CrossRef]

8. Suárez-Ojeda, M.E.; Fabregat, A.; Stüber, F.; Fortuny, A.; Carrera, J.; Font, J. Catalytic wet air oxidation of substituted phenols: Temperature and pressure effect on the pollutant removal, the catalyst preservation and the biodegradability enhancement. Chem. Eng. J. 2007, 132, 105-115. [CrossRef]

9. Ma, X.; Liu, Y.; Li, X.; Xu, J.; Gu, G.; Xia, C. Water: The most effective solvent for liquid-phase hydrodechlorination of chlorophenols over Raney Ni catalyst. Appl. Catal. B Environ. 2015, 165, 351-359. [CrossRef]

10. Zhang, W.; Wang, F.; Li, X.; Liu, Y.; Ma, J. Pd nanoparticles modified rod-like nitrogen-doped ordered mesoporous carbons for effective catalytic hydrodechlorination of chlorophenols. RSC Adv. 2016, 6, 27313-27319. [CrossRef]

11. Xia, C.; Liu, Y.; Zhou, S.; Yang, C.; Liu, S.; Xu, J.; Yu, J.; Chen, J.; Liang, X. The Pd-catalyzed hydrodechlorination of chlorophenols in aqueous solutions under mild conditions: A promising approach to practical use in wastewater. J. Hazard. Mater. 2009, 169, 1029-1033. [CrossRef] [PubMed]

12. Lan, L.; Du, F.; Xia, C. The reaction mechanism for highly effective hydrodechlorination of p-chlorophenol over a Pd/CNTs catalyst. RSC Adv. 2016, 6, 109023-109029. [CrossRef]

13. Fang, X.; Fang, D. Performance of palladium-tin bimetallic catalysts supported on activated carbon for the hydrodechlorination of 4-chlorophenol. RSC Adv. 2017, 7, 40437-40443. [CrossRef] 
14. Yu, X.; Wu, T.; Yang, X.J.; Xu, J.; Auzam, J.; Semiat, R.; Han, Y.F. Degradation of trichloroethylene by hydrodechlorination using formic acid as hydrogen source over supported Pd catalysts. J. Hazard. Mater. 2016, 305, 178-189. [CrossRef] [PubMed]

15. Kopinke, F.D.; Mackenzie, K.; Köhler, R. Catalytic hydrodechlorination of groundwater contaminants in water and in the gas phase using $\mathrm{Pd} / \gamma-\mathrm{Al}_{2} \mathrm{O}_{3}$. Appl. Catal. B Environ. 2003, 44, 15-24. [CrossRef]

16. Gómez-Quero, S.; Cárdenas-Lizana, F.; Keane, M.A. Solvent effects in the hydrodechlorination of 2,4-dichlorophenol over Pd $/ \mathrm{Al}_{2} \mathrm{O}_{3}$. AIChE J. 2010, 56, 756-767. [CrossRef]

17. Gómez-Quero, S.; Cárdenas-Lizana, F.; Keane, M.A. Effect of metal dispersion on the liquid-phase hydrodechlorination of 2,4-dichlorophenol over $\mathrm{Pd} / \mathrm{Al}_{2} \mathrm{O}_{3}$. Ind. Eng. Chem. Res. 2008, 47, 6841-6853. [CrossRef]

18. Chang, W.; Kim, H.; Lee, G.Y.; Ahn, B.J. Catalytic hydrodechlorination reaction of chlorophenols by Pd nanoparticles supported on grapheme. Res. Chem. Intermed. 2016, 42, 71-82. [CrossRef]

19. Díaz, E.; McCall, A.; Faba, L.; Sastre, H.; Ordóñez, S. Trichloroethylene hydrodechlorination in water using formic acid as hydrogen source: Selection of catalyst and operation conditions. Environ. Prog. Sustain. 2013, 32, 1217-1222. [CrossRef]

20. Kopinke, F.D.; Mackenzie, K.; Koehler, R.; Georgi, A. Alternative sources of hydrogen for hydrodechlorination of chlorinated organic compounds in water on Pd catalysts. Appl. Catal. A Gen. 2004, 271, 119-128. [CrossRef]

21. State, R.; Papa, F.; Tabakova, T.; Atkinson, I.; Negrila, C.; Balint, I. Photocatalytic abatement of trichlorethylene over $\mathrm{Au}$ and $\mathrm{Pd}-\mathrm{Au}$ supported on $\mathrm{TiO}_{2}$ by combined photomineralization/hydrodechlorination reactions under simulated solar irradiation. J. Catal. 2017, 346, 101-108. [CrossRef]

22. Di Sarli, V.; Di Benedetto, A. Effects of non-equidiffusion on unsteady propagation of hydrogen-enriched methane/air premixed flames. Int. J. Hydrog. Energy 2013, 38, 7510-7518. [CrossRef]

23. Calvo, L.; Gilarranz, M.A.; Casas, J.A.; Mohedano, A.F.; Rodriguez, J.J. Hydrodechlorination of 4-chlorophenol in water with formic acid using a Pd/activated carbon catalyst. J. Hazard. Mater. 2009, 161, 842-847. [CrossRef]

24. Cellier, P.P.; Spindler, J.F.; Taillefer, M.; Cristau, H.J. Pd/C-catalyzed room-temperature hydrodehalogenation of aryl halides with hydrazine hydrochloride. Tetrahedron Lett. 2003, 44, 7191-7195. [CrossRef]

25. Xia, C.; Liu, Y.; Zhou, S.; Yang, C.; Liu, S.; Guo, S.; Liu, Q.; Yu, J.; Chen, J. The influence of ion effects on the Pd-catalyzed hydrodechlorination of 4-chlorophenol in aqueous solutions. Catal. Commun. 2009, 10, 1443-1445. [CrossRef]

26. Dong, Z.; Le, X.; Liu, Y.; Dong, C.; Ma, J. Metal organic framework derived magnetic porous carbon composite supported gold and palladium nanoparticles as highly efficient and recyclable catalysts for reduction of 4-nitrophenol and hydrodechlorination of 4-chlorophenol. J. Mater. Chem. A 2014, 2, 18775-18785. [CrossRef]

27. Shao, Y.; Xu, Z.; Wan, H.; Wan, Y.; Chen, H.; Zheng, S.; Zhu, D. Enhanced liquid phase catalytic hydrodechlorination of 2,4-dichlorophenol over mesoporous carbon supported Pd catalysts. Catal. Commun. 2011, 12, 1405-1409. [CrossRef]

28. Molina, C.B.; Pizarro, A.H.; Casas, J.A.; Rodriguez, J.J. Aqueous-phase hydrodechlorination of chlorophenols with pillared clays-supported Pt, Pd and Rh catalysts. Appl. Catal. B Environ. 2014, 148-149, 330-338. [CrossRef]

29. Hartman, R.L.; McMullen, J.P.; Jensen, K.F. Deciding whether to go with the flow: Evaluating the merits of flow reactors for synthesis. Angew. Chem. Int. Ed. 2011, 50, 7502-7519. [CrossRef]

30. Gutmann, B.; Cantillo, D.; Kappe, C.O. Continuous-flow technology-a tool for the safe manufacturing of active pharmaceutical ingredients. Angew. Chem. Int. Ed. 2015, 54, 6688-6728. [CrossRef]

31. Naber, J.R.; Buchwald, S.L. Packed-bed reactors for continuous-flow C-N cross-coupling. Angew. Chem. Int. Ed. 2010, 49, 9469-9474. [CrossRef] [PubMed]

32. Kumar, U.; Panda, D.; Biswas, K.G. Non-lithographic copper-wire based fabrication of micro-fluidic reactors for biphasic flow applications. Chem. Eng. J. 2018, 344, 221-227. [CrossRef]

33. Tsubogo, T.; Ishiwata, T.; Kobayashi, S. Asymmetric carbon-carbon bond formation under continuous-flow conditions with chiral heterogeneous catalysts. Angew. Chem. Int. Ed. 2013, 52, 6590-6604. [CrossRef] [PubMed]

34. Rossetti, I. Continuous flow (micro-)reactors for heterogeneously catalyzed reactions: Main design and modelling issues. Catal. Today 2018, 308, 20-31. [CrossRef] 
35. Xiong, J.; Ma, Y.; Yang, W.; Zhong, L. Rapid, highly efficient and stable catalytic hydrodechlorination of chlorophenols over novel Pd/CNTs-Ni foam composite catalyst in continuous-flow. J. Hazard. Mater. 2018, 355, 89-95. [CrossRef] [PubMed]

36. Liu, W.; Rodriguez, P.; Borchardt, L.; Foelske, A.; Yuan, J.; Herrmann, A.K.; Geiger, D.; Zheng, Z.; Kaskel, S.; Gaponik, N.; et al. Bimetallic aerogels: High-performance electrocatalysts for the oxygen reduction reaction. Angew. Chem. Int. Ed. 2013, 52, 9849-9852. [CrossRef] [PubMed]

37. Ding, H.; Shi, X.Z.; Shen, C.M.; Hui, C.; Xu, Z.C.; Li, C.; Tian, Y.; Wang, D.K.; Gao, H.J. Synthesis of monodisperse palladium nanocubes and their catalytic activity for methanol electrooxidation. Chin. Phys. B 2010, 19, 106104.

38. Jadbabaei, N.; Ye, T.; Shuai, D.; Zhang, H. Development of palladium-resin composites for catalytic hydrodechlorination of 4-chlorophenol. Appl. Catal. B Environ. 2017, 205, 576-586. [CrossRef]

39. Casanovas, A.; Domínguez, M.; Ledesma, C.; López, E.; Llorca, J. Catalytic walls and micro-devices for generating hydrogen by low temperature steam reforming of ethanol. Catal. Today 2009, 143, 32-37. [CrossRef]

40. Xiong, J.; Dong, X.; Dong, Y.; Hao, X.; Hampshire, S. Dual-production of nickel foam supported carbon nanotubes and hydrogen by methane catalytic decomposition. Int. J. Hydrog. Energy 2012, 37, 12307-12316. [CrossRef]

41. Yu, Z.; Chen, D.; Tøtdal, B.; Zhao, T.; Dai, Y.; Yuan, W.; Holmen, A. Catalytic engineering of carbon nanotube production. Appl. Catal. A. Gen. 2005, 279, 223-233. [CrossRef]

42. Yuan, G.; Keane, M.A. Liquid phase hydrodechlorination of chlorophenols over $\mathrm{Pd} / \mathrm{C}$ and $\mathrm{Pd} / \mathrm{Al}_{2} \mathrm{O}_{3}: \mathrm{A}$ consideration of $\mathrm{HCl} /$ catalyst interactions and solution $\mathrm{pH}$ effects. Appl. Catal. B Environ. 2004, 52, 301-314. [CrossRef]

43. Keane, M.A. A review of catalytic approaches to waste minimization: Case study-liquid-phase catalytic treatment of chlorophenols. J. Chem. Technol. Biotechnol. 2005, 80, 1211-1222. [CrossRef]

44. Gómez-Quero, S.; Cárdenas-Lizana, F.; Keane, M.A. Liquid phase catalytic hydrodechlorination of 2,4-dichlorophenol over $\mathrm{Pd} / \mathrm{Al}_{2} \mathrm{O}_{3}$ : Batch vs. continuous operation. Chem. Eng. J. 2011, 166, 1044-1051. [CrossRef]

45. Singh, P.; Kulkarni, M.V.; Gokhale, S.P. Enhancing the hydrogen storage capacity of Pd-functionalized multi-walled carbon nanotubes. Appl. Surf. Sci. 2012, 258, 3405-3409. [CrossRef] 